\title{
Big Social Data Analytics of Changes in Consumer Behaviour and Opinion of a TV Broadcaster
}

\author{
Hennig, Anna; Åmodt, Anne-Sofie; Hernes, Henrik; Nygårdsmoen, Helene Mejer; Arenfeldt \\ Larsen, Peter; Mukkamala, Raghava Rao; Flesch, Benjamin; Hussain, Abid; Vatrapu, Ravi
}

Document Version

Final published version

Published in:

Proceedings - 2016 IEEE International Conference on Big Data, Big Data 2016

Publication date:

2016

License

CC BY-NC-ND

Citation for published version (APA):

Hennig, A., Amodt, A-S., Hernes, H., Nygårdsmoen, H. M., Arenfeldt Larsen, P., Mukkamala, R. R., Flesch, B., Hussain, A., \& Vatrapu, R. (2016). Big Social Data Analytics of Changes in Consumer Behaviour and Opinion of a TV Broadcaster. In R. Ak, G. Karypis, Y. Xia, X. T. Hu, P. S. Yu, J. Joshi, L. Ungar, L. Liu, A-H. Sato, T. Suzumura, S. Rachuri, R. Govindaraju, \& W. Xu (Eds.), Proceedings - 2016 IEEE International Conference on Big Data, Big Data 2016 (pp. 3839-3848). [7841057] IEEE.

Link to publication in CBS Research Portal 


\title{
Big Social Data Analytics of Changes in Consumer Behaviour and Opinion of a TV Broadcaster
}

\author{
Anna Hennig ${ }^{1}$, Anne-Sofie Åmodt ${ }^{1}$, Henrik Hernes ${ }^{1}$, Helene Mejer Nygårdsmoen ${ }^{1}$, Peter Arenfeldt Larsen ${ }^{1}$, \\ Raghava Rao Mukkamala ${ }^{1}$, Benjamin Flesch ${ }^{1}$, Abid Hussain ${ }^{1}$ and Ravi Vatrapu ${ }^{1,2}$ \\ ${ }^{1}$ Centre for Business Data Analytics, Copenhagen Business School, Denmark \\ ${ }^{2}$ Westerdals Oslo School of Arts, Comm \& Tech, Norway \\ $\{$ rrm.itm, rv.itm\}@cbs.dk
}

\begin{abstract}
This paper examines the changes in consumer behaviour and opinions due to the transition from a public to a commercial broadcaster in the context of broadcasting international media events. By analyzing TV viewer ratings, Facebook activity and its sentiment, we aim to provide answers to how the transition from airing Winter Olympic Games on NRK to TV2 in Norway affected consumer behaviour and opinion. We used text classification and visual analytics methods on the business and social datasets. Our main finding is a clear link between negative sentiment and commercials. Despite positive change in customer behaviour, there was a negative change in customer opinion. Based on media events and broadcaster theories, we identify generalisable findings for all such transitions.
\end{abstract}

Index Terms-Television Viewer behaviour, Big Social Data, Facebook, Big Data Analytics, Social Set Analysis, Social Set Visualiser, Text Classification

\section{INTRODUCTION}

Fierce and growing competition within sports broadcasting has led to bidding wars and the cost of media event broadcasting rights increasing [1]. For the 2014 Winter Olympic Games held in Russia, the largest commercial television station in Norway, TV2, got the broadcasting rights for Norway. Previously all the 28 consecutive Olympic Games were broadcasted by NRK, the Norwegian government-owned and publicly funded Television operator. Further, the Olympic broadcasting rights from 2018 to 2024 has been awarded to Discovery Communications ${ }^{1}$.

In recent years the Olympic Games themselves have been hit by political, budgetary, doping and organizational scandals. Adding to this, in Norway, the transition from NRK to TV2 has resulted in massive discussions regarding commercial breaks, the performance of commentators and about the overall change. We have conducted an Social Set Analytical event study investigating the Norwegian television viewers' behaviour and opinions before, during and after the Olympic Winter Games of 2014. By doing this we hope to provide meaningful facts, actionable insights and valuable outcomes regarding public opinion and behaviour in relation to media events.

Research shows that sports are often being portrayed and communicated to enhance national identity and a sense of

\footnotetext{
${ }^{1}$ IOC awards all TV and multiplatform broadcast rights in Europe to Discovery and Eurosport for 2018-2024 Olympic Games
}

national unity and belonging [2], [3]. In 2011 the consultancy firm AT Kearney published a report stating that around $€ 450$ billion( $\$ 620$ billion) is spent in the sports industry every year $^{2}$.As such, sports is important for broadcasters, and the viewers behaviour and opinion in relation to broadcasted events might have significant impact on their success. To be granted a license to broadcast a sports event like Winter Olympics can be a way to attract new viewer groups. However, the quality of broadcasting might determine the broadcaster's ability to retain viewers after the end of the event.

The acquisition of TV broadcasting rights is not an easy decision as the Norwagian broadcasting rights for the 2014 Winter Olympics are estimated to be between NOK 50-100 million (approximately $€ 5.5-11$ million). Accordingly, the nature of sports broadcasting is changing, leading to massive reactions in social media, especially regarding overall performance, criticism of commentators and commercial breaks. This paper addresses the following research questions.

\section{A. Research Questions}

1) How did consumer behaviour of the TV2 network change as a result of broadcasting the Olympic Winter Games of 2014 ?

2) How was consumer opinion of the TV2 network affected during the Olympic Winter Games of 2014?

3) How did consumer opinion towards TV2 and NRK differ during the Olympic Winter Games of 2014 ?

\section{RELATED WORK}

Multiple academic articles have been written about the sports broadcasting ranging from industry wide coverage relating to subjects such as broadcasting rights and innovation, to narrow research topics focusing on specific channels or events.Noll [4] investigates how game coverage, revenues and competitive balance are affected by allocation of broadcasting rights and inter-channel competition. Dayan and Katz [5] highlight the wide reach of media events such as Olympic Games. Their research explains why there is a massive interest and competition among broadcasters for the rights of these kinds of events. In a recent study, Ugulen [6], studied TV2 and their broadcasts in the context of 2014 Winter Olympic

\footnotetext{
${ }^{2}$ The Sports Market - AT Kearney
} 
Games of 2014 and finds that despite not being the game changer TV2 hoped for, they still attained more followers on Facebook pages, likes on posts and high viewer numbers.

Regarding a sports event transitioning from a public broadcaster to a private broadcaster, Scherer and Sam [7] investigated the issue of private broadcasters in their investments to achieve the exclusive rights for nationally important sport events, especially through the increased digitization in the recent years. This has been achieved in 2009 by Sky TV, a pay TV network in New Zealand. As such, the traditional role that public broadcasting had played for decades in broadcasting big sport events live and free-to-air, has been eroded [7]. In contrast, Scherer and Whitson [8] showed how the public broadcaster in Canada Canadian Broadcasting Corporation was able to maintain the sports rights for the National Hockey League (NHL). It was argued, that providing this sports event through a public broadcaster is of special importance to the Canadian citizens due to cultural citizenship, although subscription to the private broadcasters has increased [8].

[9] investigated the relationship between television, its audiences and social media around the creation of social TV events. The study applied a quantitative approach, measuring the volume of Twitter messages before, during and after two different types of television programmes, i.e. Reality TV and sports broadcasts, as well as a brief comparisons including data collected from Facebook. Thus, similar to us they used social media data to investigate behaviour [9]. The study found that there was a trend showing key activity both during and towards the end of a broadcast, i.e. that viewers used Twitter, or Facebook, while watching the event [9]. Although their main focus was on Twitter data, the comparison with Facebook showing similar patterns indicates that this could also be true for our data. Moreover, their findings indicate that social media data can be considered representative data when measuring opinion and behaviour during sport events.

Regarding text analytics and visual analytics of big social data, [10] monitored infectious diseases. Especially Facebook has been used in recent years to express opinions through comments, posts, likes and shares. The collection and analysis of these data for conducting event studies has been accomplished in many studies before, including an analysis of the interaction of two fan bases on crowdsourcing with the companies before, during and after a product was launched was conducted [11].

Furthermore the study of Emotions from text: machine learning for text-based emotion prediction [12] focuses on the examination and classification of emotional content of 22 fairy tales shows by using supervised machine learning. This shows, that supervised machine learning can be used in different contexts and for different sources, including Facebook comments like in our study.

\section{Methodology}

\section{A. Case Company Description}

The Norwegian television network TV2 was given regulatory permission to broadcast in 1991 and was the fourth player to enter the industry. TV2 has three principal areas of focus; sports, news and entertainment. In 2014, TV2 Norway had a revenue amounting EUR 441 million, an operating profit of EUR 36,3 million, which is an 11 per cent increase from 2013 [13]. In 2013, the company had a total of 878 FTEs. Prior to the Sochi Games, a team of 200 employees was assembled to plan and work towards covering the Olympics. TV2 provides news, sports and entertainment on several platforms, and aim to become the largest interactive Norwegian multimedia provider. In 2014, this was achieved in the 20-49 year segment with a viewer share of 30.9 percent [14].

\section{B. Dataset Description}

The analysis of TV2 and their Olympic broadcasting is based on three data sets; TNS Gallup ratings data on TV2, Facebook data from 'TV2 Sporten' and Facebook data from 'NRK Sport'. The data sets are selected based on the research questions. The three data sets together consist of 7.532 million data points.

1) TNS Gallup data: The dataset is delivered by TNS Gallup, the official provider of statistics regarding Norwegian television viewer numbers [14]. The company analyses batch data with a derived mathematical structure, using a real-time data collection sample containing a minimum of 1,000 households. In 2015, the total sample population consists of approximately 2.027.000 individuals from a 4.025.000 universe. As such, TNS Gallup is an aggregated data provider [15]. The original dataset consists of approximately 250 variables, including age, gender, income, occupation, and political opinion (TNS Gallup AS 2014). The sample data has a $95 \%$ confidence interval with a margin of error of approximately 100,000 viewers (TNS Gallup AS 2014). We requested an extraction of data based on the TNS television Code Book and Program Manual and the details of the datasets of NRK and TV2 is shown in Table I. For the pre-event period of May 7th 2013 to February 6th 2014, as well as the post-event period of February 24th 2014 to November 23rd 2014, the requested data is delimited to the daily TV2 and sport news. The data extracted for the event-window, as shown in table I, includes all OWG related programs for TV2 and NRK. Both datasets contain a total of 114 different categories within eight variables about the viewers. With this extraction, our TNS data set contains around 918,000 datapoints (805,068 (before and after) $+113,544$ (during))

\begin{tabular}{|l|l|l|}
\hline & NRK & TV2 \\
\hline From & 07.02 .2014 & 07.02 .2014 \\
\hline To & 23.02 .2014 & 23.02 .2014 \\
\hline Channels & NRK1, NRK2, NRK3 & $\begin{array}{l}\text { TV2, TV2 Zebra, TV2 } \\
\text { Sportskanalen }\end{array}$ \\
\hline Programs & $\begin{array}{l}\text { All Olympic broadcasts, } \\
\text { sports news, Olympic } \\
\text { Studios }\end{array}$ & $\begin{array}{l}\text { All Olympic broadcasts, } \\
\text { sports news, Olympic } \\
\text { Studios and Senkveld fra } \\
\text { OL }\end{array}$ \\
\hline Variables & $\begin{array}{l}\text { Sex, rural/urban, work status, education, age group, } \\
\text { family type, household income, personal income }\end{array}$ \\
\hline \multicolumn{2}{|c|}{ Table I } \\
\hline \multicolumn{2}{|c|}{ COMPANY DATA OF NRK AND TV2 DuRING THE EvENT }
\end{tabular}

COMPANy DATA OF NRK AND TV2 DURING THE EVENT 
2) Facebook Data: The Facebook dataset consists of posts, comments, likes, and shares and was fetched on demand using SODATO [16], [17] for batch analysis. Data from Facebook pages are structured in a chronological order based on wall posts. This entails that comments, shares and likes are attached to the relevant post, despite their creation date being unconnected to the original post. As such, the data is arranged in a hierarchical order, where posts represent the roots, and comments, shares and likes represent the nodes. Hence, the social data has a tree structure.

\begin{tabular}{|l|r|r|}
\hline & TV2 Sporten & NRK Sport \\
\hline From & 01.01 .2012 & 01.01 .2012 \\
\hline To & 19.10 .2015 & 19.10 .2015 \\
\hline Total Posts & 30,396 & 13,944 \\
\hline Total Comments & 381,914 & 94,323 \\
\hline Total Likes & $2,915,451$ & $1,472,717$ \\
\hline Total Shares & 105,431 & 104,763 \\
\hline Total Unique Actors & 393,037 & 364,917 \\
\hline \multicolumn{3}{|c|}{ Table II }
\end{tabular}

Social Data Corpus of Facebook Pages TV2 Sporten AND NRK Sport

\section{Data Analysis Process}

Data mining is a methodological process containing a sequence of stages or phases [18]. Accordingly, it is not a set of activities that can be performed in an arbitrary order. A common process commence with formulation of research questions, and ends with communication of results. The methodological process is often repeated from top to bottom, as communication of results often leads to the development of new research questions and suggestions for future work. Our data analysis process is depicted in Figure 1 below

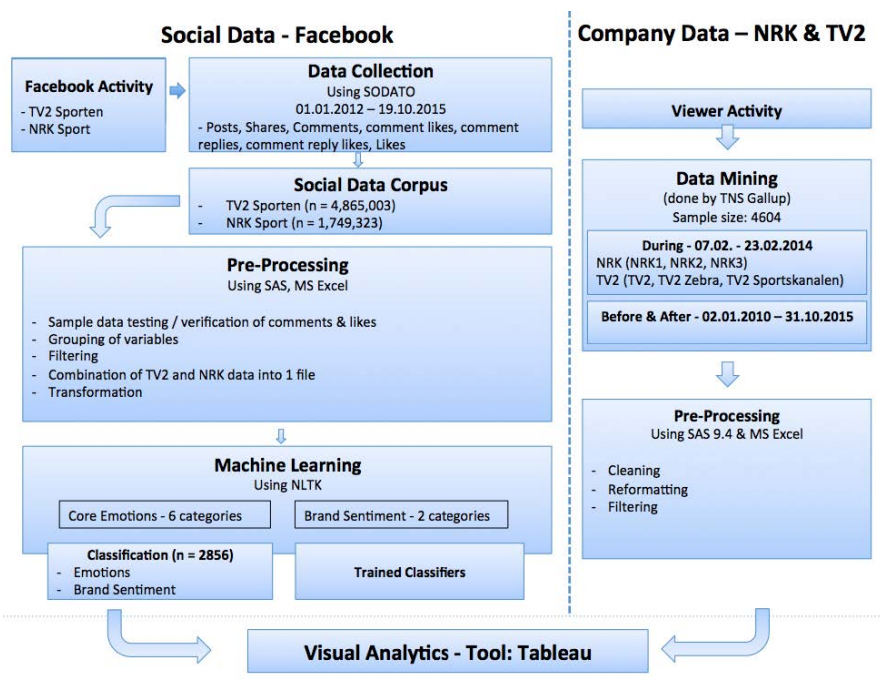

Figure 1. Data Analysis Process Diagram

As part of the methodology we have applied machine learning algorithms for the text classification of the Facebook text corpus containing posts and comments (mostly written in the Norwegian Language) from both the walls. Text classification approach is a supervised machine learning technique and it can be defined as a process where assigning a predefined category of labels to new documents based on probabilistic measure of likelihood using a training set of labelled documents [19]. Out of several approaches available in text classification domain, we have chosen a simple text classification method [20] based on Bayes rule that relies on a simple representation of documents using bag of words approach. For the text classification. The authors have manually coded around 24,000 Norwegian texts from Facebook post and comments against two different models: Basic Emotions and Brand Sentiment. As part of Basic Emotions, we have used 6 different labels: Anger, Disgust, Fear, Joy, Sadness, Surprise to classify the texts, where as for Brand Sentiment, we have used standard sentiment labels: Positive, Negative and Neutral. All the manually encoded texts with the respective labels for the models have used to train the classifier using Natural Language Toolkit (NLTK) [21] using Python programming language. When once the classifier has been sufficiently trained, we have used the classifier to classify the whole text corpus containing 44,000 Facebook posts and 475,000 comments. Finally the results of the text classification along with other data analysis were interpreted using the visual analytics tool Tableau.

\section{RESUlTS AND FINDINGS}

\section{A. Meaningful Facts}

1) Event Related Spikes: Figure 3 displays the total Facebook activity of the Facebook pages TV2 Sporten (dark blue) and NRK Sport (light blue) from May 7th 2013 to November 11th 2014. There is a spike in the data set corresponsing to the event window, framed by relatively consistent before- and after- event periods showing lower levels of activity. Further, the before and after period are symmetrical and shows a lower level of activity. Moreover, the graph portrays a higher overall level of activity for TV2 than for NRK.

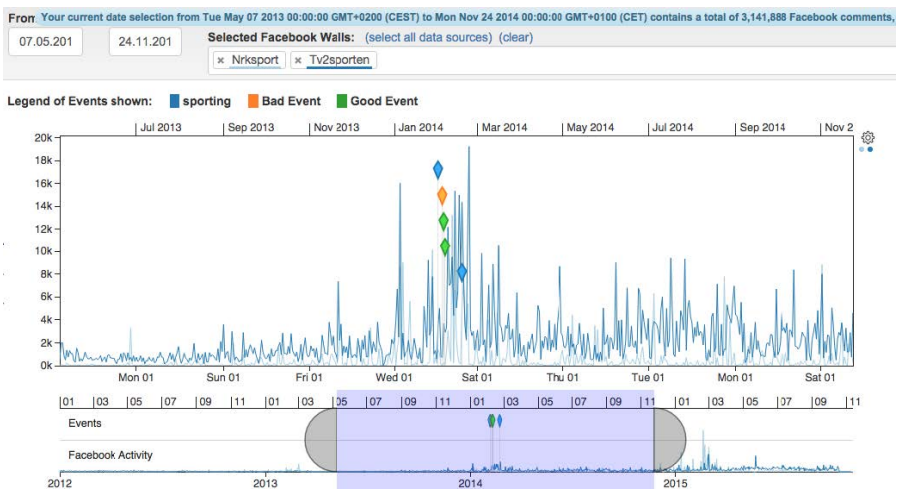

Figure 2. Temporal distribution of total Facebook activities for NRK Sport and TV2 Sporten

2) Seasonal Variation Patterns: Figure 3 displays an overview of monthly total ratings for TV2 Sports News in the time period 2010 to 2015 . Visualizing several years of data allows the display of seasonal variations, as portrayed in TV2 Sporten rating numbers. During the summer months 
ratings generally fall below the yearly average, while winter months display higher rating numbers. In contrast, difference from the average displays seasonal variation. Combined, the two figures portray that there is a clear seasonal variation.

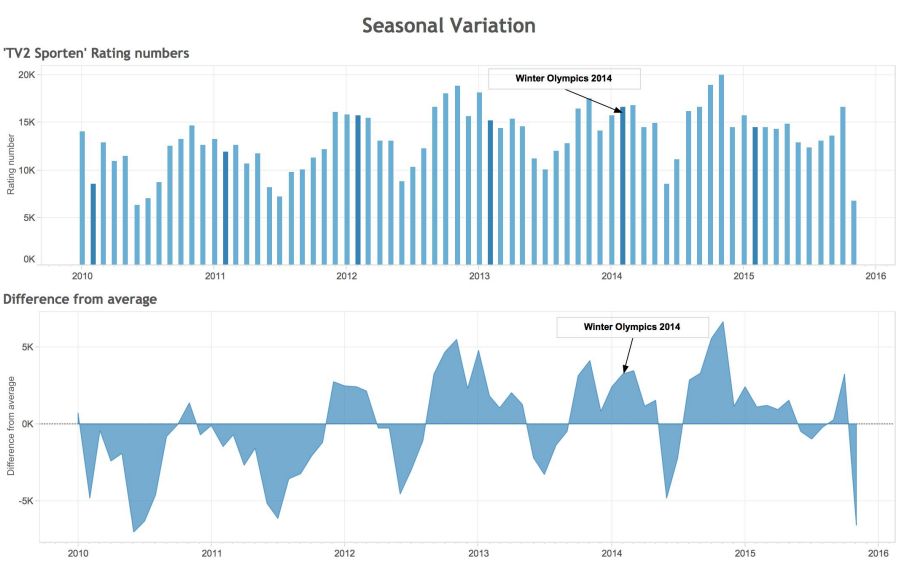

Figure 3. Seasonal Variation of TV2 Sports News

When zooming into ratings per month as shown in Figure 4, data revealed support for the observations of seasonal fluctuations made in Figure 3. The increased ratings during winter months could be caused by dropping temperatures, entailing that people are spending more time indoors. A correspondingly valid argument might be the popularity of winter sports in Norway. This is even more pressing when looking at the numbers from the last Olympics. The increase during the Olympics window in 2014 show that the total rating ended at $16,590,000$, around 20 percent above the average $(13,724,000)$ for February. The rating numbers for February 2010 when the Olympics aired on NRK, are in strong contradiction to the values from February 2014. A rating number of 8,519,000 and 40 percent down from the average in February 2010, show that the negative impact is even stronger than the positive impact. As such, broadcasting Olympics increases the broadcasters rating numbers during the event itself, while not broadcasting them decreases ratings.

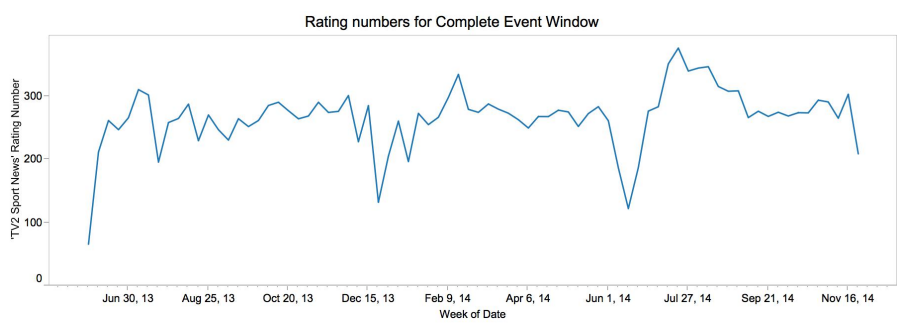

Figure 4. Total Rating Numbers for TV2 Sports News

3) Demographic and Temporal Patterns: Figure 5 shows that the age group 60+ is the group with highest ratings during the Olympics. This makes sense, as different Olympic programs air at various hours and days of the week. Due to time difference between Norway and Russia, most events were broadcast during the day in normal working hours. Thus, retired citizens might have the option to watch, as they do not have obligations like school and work. However, the underlying data do not include mobile device ratings.

Additionally, the graph shows a peak on Sunday February 9th. This makes sense as the day contains both female biathlon and mens cross country, which are two of the most watched sports of the Olympics, accordingly indicating high ratings. Additionally, Sundays are the most watched day (as shown in Bar Chart Average Rating Number by Day of Week). It is further observed that ratings are high in the beginning of the event, indicating increased interest early in the event window.

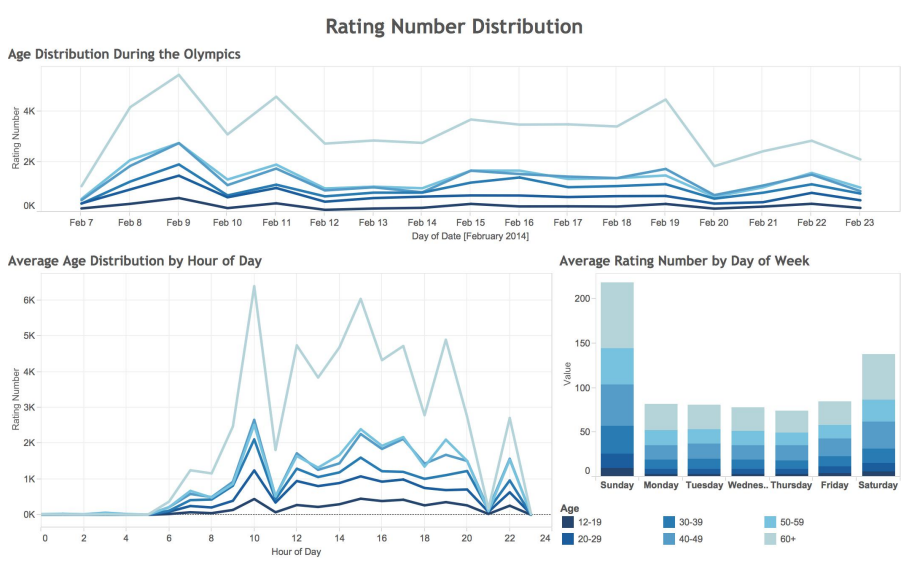

Figure 5. Rating Numbers Distribution

There is a significant increase in unique actors during the event compared to before and after. This makes sense, and is apparent in Figure 6 both in the graph on the LHS, but also in the graph on the RHS, as During is only 2.5 weeks compared to before which is 34 weeks. Further the graph on the RHS shows an actor analysis depicting unique users and their activity on the relevant Facebook wall before, during and after the event. As such, the graph is showing that of the 66,714 unique actors actively contributing with content to TV2 Sporten during the event, 42.9 percent were retained after the event. Of these, 64.2 percent were also active on TV2 Sporten before the event.

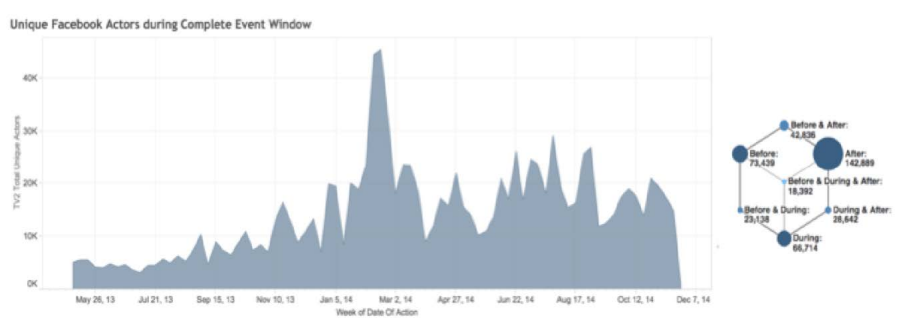

Figure 6. Unique Facebook Actors During Complete Event Window TV2 Sporten

4) Sentiment Distrisbution: "Good Event" was identified as one where a Norwegian athlete won a gold medal and 
the commentator cried during live broadcasting. This celebration spurred massive media coverage. Based on a three day window showing the "Good Event", the data show no significant increase in positive posts and comments. Figure 7 displays positive, negative and neutral posts and comments on TV2 Sporten during the Olympics. No significant increase in number of posts and comments is evident on February 11th, where the Good Event happened. One would expect Good Event to supercede other days in number of positive posts and comments, however, the opposite is true. Surprisingly, days both prior and post February 11th had significantly more posts and comments, as shown in graph Sentiment during Good Event. Rationally, one would expect events with massive media coverage to increase social engagements, however the opposite is evident in Good Event.

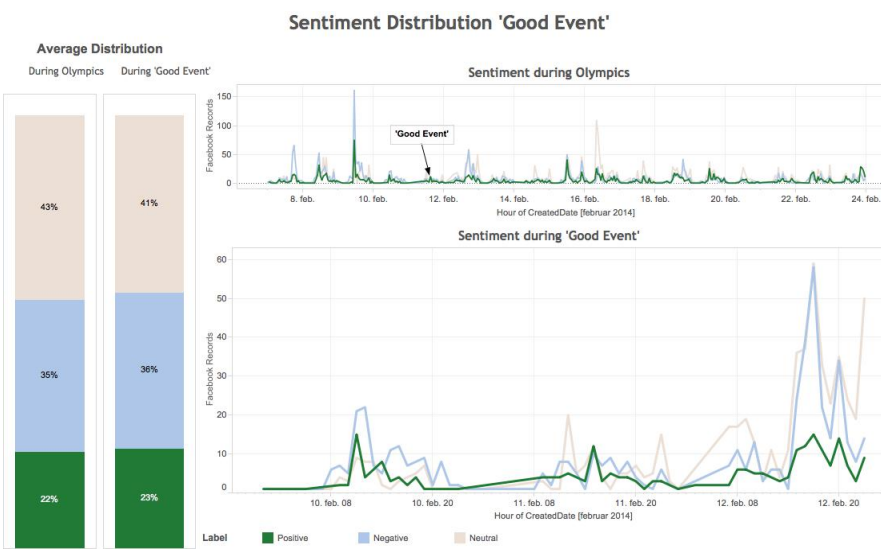

Figure 7. Distribution of Sentiment during Good Event

5) Emotional Patterns: In figure 8, the graph Overview: Event Window illustrate the distribution of emotions during the Olympics (A) over time, while the stacked bar (B) displays the distributed average for the same period. Over time, the distribution differs according to specific events. For example, on the 16th Norway won gold in Cross country for Men there is a significant spike in joy resulting in it being the dominating emotion on that exact date. Similar finding is on the 8th, where Norway won gold in Snowboarding. This joy spike is not as high, which can be explained by the fact that this show was viewed by less people than the Cross Country event. If joy correlate with winning, one could assume that losing would correlate with anger or sadness. However, the only point where anger surpasses joy is on the 9th, i.e. the Bad Event peak that is caused by commercials. There is no significant spikes in sadness for the Olympic period, indicating that the same emotion correlation is not true for losing as it is for winning.

Portrayed in stack bar B, fear is interestingly the most common and dominating emotion. In fact, the Cross Country win on the 16th is the only point during Olympics where fear is not the most dominating emotion. This can indicate that sport viewers worry significantly about future events rather than being angry or sad about past results. However, since many of the posts and comments in question are neutral towards TV2

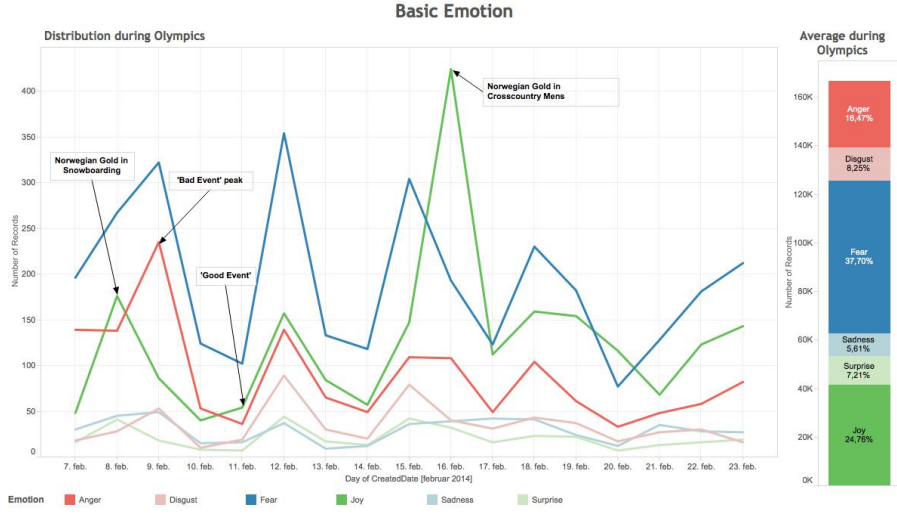

Figure 8. Basic Emotion TV2 Sporten

and rather contain opinion on other events such as winning or losing, they are irrelevant to measuring both opinion and behaviour towards TV2.

6) Temporal Patterns: The line graph in figure 9 display total monthly Facebook activity on NRK Sport and TV2 Sporten for the complete event window, with associating trendlines. It is easily illustrated that both trendlines are experiencing positive growth rates in overall activity, however, TV2 has a steeper slope than NRK. On average TV2 attracts an additional 172 Facebook activities per month, whereas NRK only attracts 30 activities.

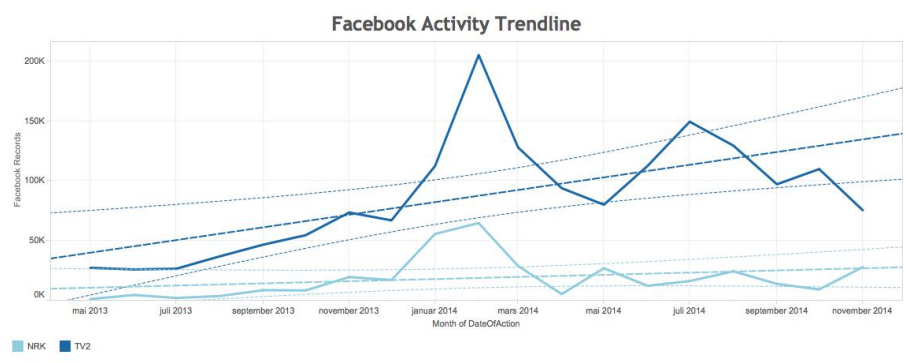

Figure 9. Facebook Activity Trendline

In figure 10, graph During the Olympics by Day shows how activity evolves during the event, in regards to ratings (bars) and Facebook activity respectively (line). Correspondingly, graph Correlation shows that the two variables have a positive correlation, indicating that when ratings increase, Facebook activity increases too. However, since the coefficient is approximately 0.39 , it indicates only a moderate positive relationship between the two variables. As TV2 are looking to become an interactive platform, and broadcasting the Olympics is part of this effort, these findings are both interesting and important.

During the event window the most common words posted on the two broadcasters Facebook walls differ as retrieved uisng a research prototype tool Social set visualizer Tool (SoSeVi) [22], [23]. Figure 11 exhibit Commercial (reklame) as the most common word for TV2 used 799 times (reklame 651 and reklamen 148). This is followed by Congratulations 


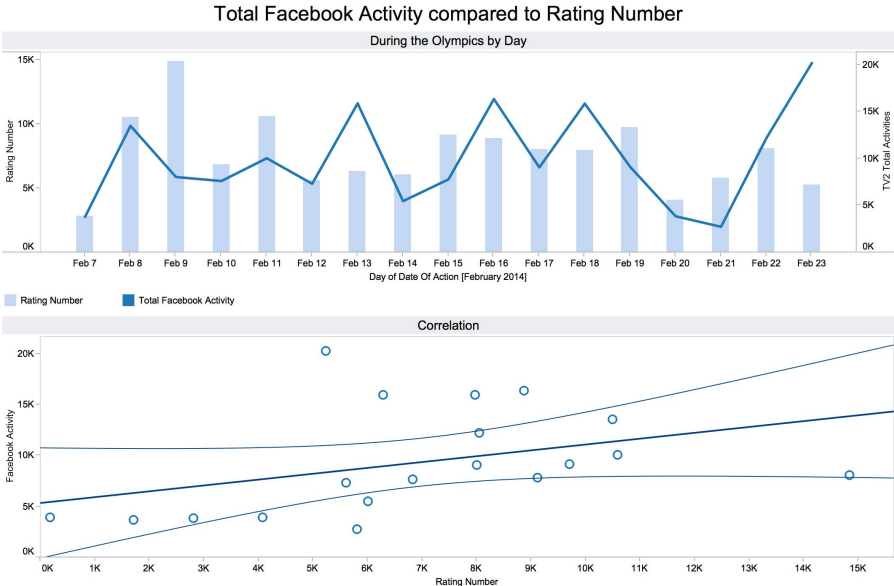

Figure 10. Total Facebook Activity Compared to Rating Number

(gratulerer) as the second most common word with 491 occurrences (gratulerer 403 and gratulere 88). Simultaneously, the most commonly used word on NRK Sport is Congratulations occurring 620 times (gratulerer 529 and gratulere 91). This indicates activity on NRK Sport coherent with the successful performance of Norwegian athletes during the Olympics. Simultaneously, the TV2 word cloud illustrate massive attention attributed to TV2s timing of commercial slots. As such, these two visualizations validate and directly relates to the research question X, both in relative and absolute terms. The two word clouds further provide face validity as discussed in section 5.1.1, as both clouds clearly exhibit relevant words for a sports related Facebook page.

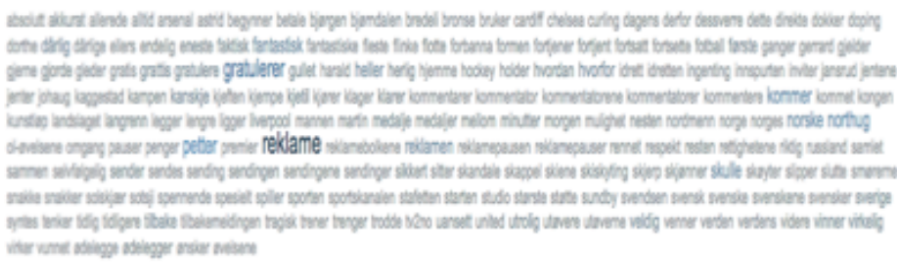

Figure 11. Word Cloud from SoSeVi of TV2 Sporten Facebook Wall During the Bad Event $($ Reklame $=$ Commercial $)$

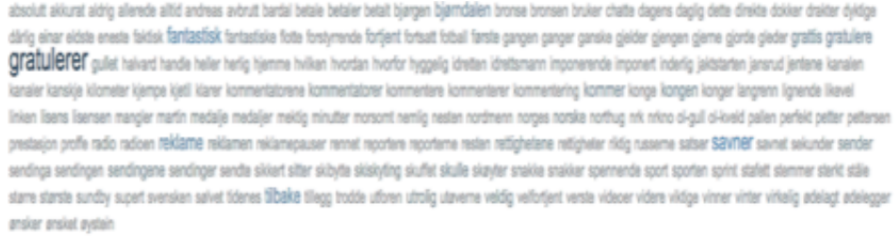
niver niut onian

Figure 12. Word Cloud from SoSeVi of NRK Sport Facebook Wall During the Bad Event $($ Gratulerer $=$ Congratulations, Fantastisk $=$ Fantastic $)$

When narrowing in on the "Bad Event: where TV2 aired commercials interrupting several programs, the word clouds above (Figure 11 and 12) illustrate and supports the above findings. During the entire event window there are multiple enhanced words in the two word clouds. When narrowing down the time frame, a clear trend is depicted. The TV2 word cloud shows that the word commercial is used significantly more than any other word with 722 appearances (of a total of 799). The NRK word cloud indicates 188 congratulatory messages towards the successful athlete, while simultaneously expressing words such as missing (savner) (68 times) and back (tilbake) (43 times). There are 59 occurrences of the word commercial on NRK Sport. However, as NRK is subsidized by the government and prohibited from airing commercials, one can assume that the three words commercial, missing and back indicate a longing for Olympic broadcasts on NRK. As such, it indicates that actors are preferring NRK over TV2.

7) Positive, negative and neutral sentiment activity TV2 - during the Olympics: Figure 13 Graph 1 (Sentiment for complete event window by month) displays the number of positive, negative and neutral sentiments towards TV2 Sporten during the complete event window. It is clear that positive and negative sentiments increase during the Olympics while neutral decreases. Graph 2 (Sentiment During Olympics by Hour) shows that there is high negative activity during the time period specified as Bad Event. As further elaborated in the introduction, people were upset by the timing of commercials. There are multiple spikes in sentiment activity. Particularly, it is interesting that three of the biggest spikes during the whole olympics are occurring during Bad Event.

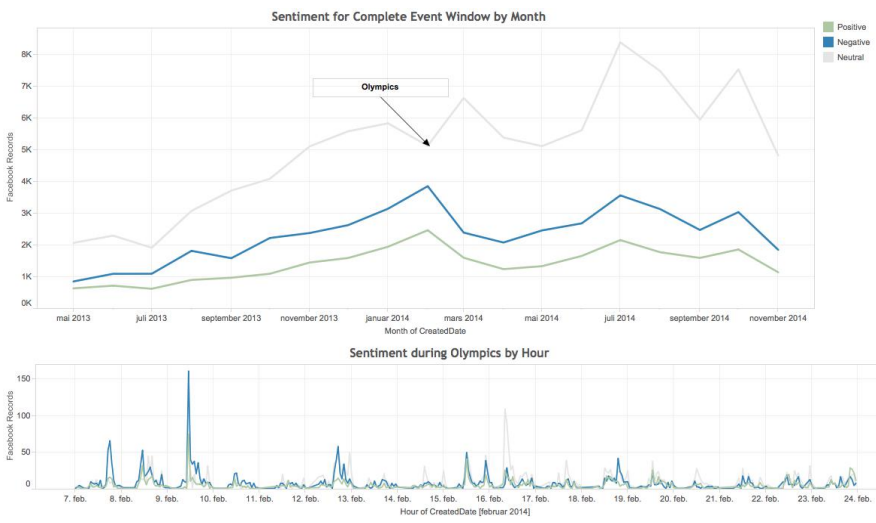

Figure 13. Sentiment Towards 'TV2 Sporten'

8) Bad Event Sentiment Factors: Figure 13 shows the factors explaining Bad Event sentiment. The graph Positive/Negative Sentiment during Bad Event with corresponding programs is a closer depiction of Bad event window, visualizing that TV2 has more negative than positive posts and comments during the relevant 72 hours. All three days demonstrate a steep incline in negative posts and comments corresponding to the time of a specific event (opening ceremony, slopestyle final, and mens skiathlon). The size of the relevant peaks coincide with the total ratings per event, as illustrated in Bad Event Program Viewing Number. This indicate that the number of posts and comments are correlated with the total number of viewers. For example, Cross Country Skiathlon aired on February 9th 
had the highest rating numbers, and correspondingly February 9th had the highest number of negative posts and comments. The graph further depicts an increase in positive posts and comments corresponding to the same three events. However, these positive comments are not in the same way reflecting the difference in viewer numbers.

Interestingly, at the time of the third and highest spike in negative comments portrayed in Figure 14, number of posts surpasses number of comments (and comment replies). This indicates that on the third day people actively sought out TV2 Sportens Facebook wall, as oppose to for example comment on posts in news feed. Moreover, posts generate more activity and this could thus be seen as both cause and effect of the high spike.

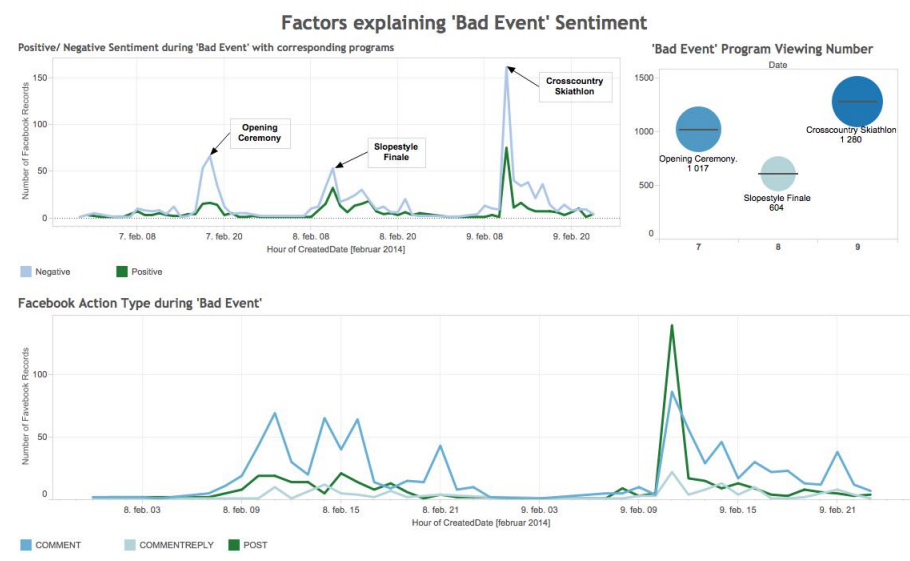

Figure 14. Factors Explaining 'Bad Event' Sentiment

9) Ratings by Sports and Gender: Ratings by field and gender, as displayed in Figure 15, shows the popularity of different fields divided by the athletes gender. First of all Cross Country skiing and Skiathlon are by far the biggest sports fields bringing approximately 50 percent of the total viewer numbers. In addition, it shows that sports events with male athletes are more popular than their female counterparts. Although neither of these findings are contradictory, Biathlon for women stands out. Although single events showing male biathlon athletes have more viewers, female biathlon drew more viewers than male biathlon in total. Even if the third most watched show on TV2 in 2014 is $30 \mathrm{~km}$ biathlon for men, the female events had a total of 30 percent more viewers than the males. In retrospect, we know that the males got two gold medals compared to the women with one silver and two bronze, so there should be no specific favour to the female part of the sport in terms of sportly outcome.

10) Comparison of Live-Broadcasting and Re-run Programs: The top bar chart Overall share of rating numbers in Figure 16 shows rating numbers for all live broadcasts and reruns during the Olympics. Obviously, the original broadcasts had significantly more viewers than their re-runs. The bottom bar chart Skiathlon Re-run in Figure 16 presents a case, where a Skiathlon event and the following shows, including its re-run, reveals the variation in ratings. In this case, the

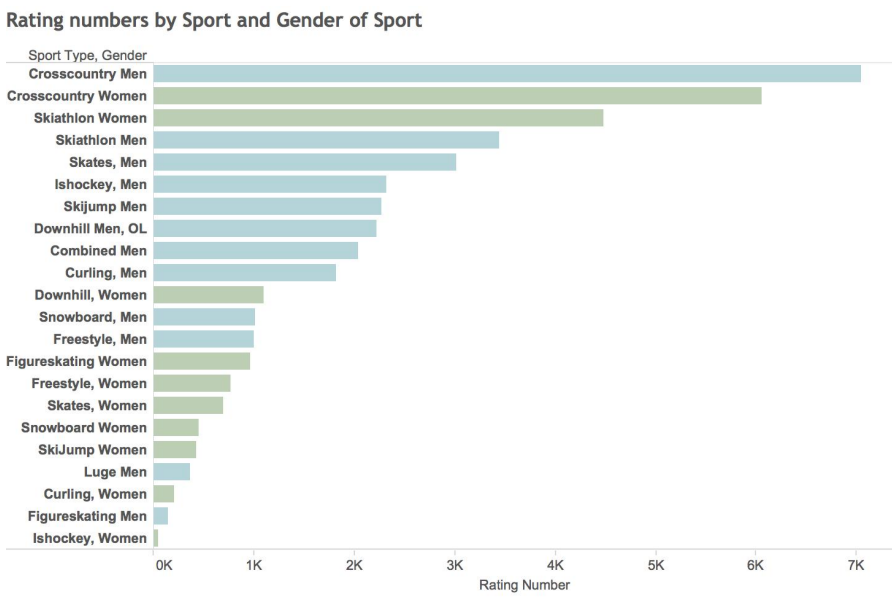

Figure 15. Rating Numbers by Sport and Gender of Sport

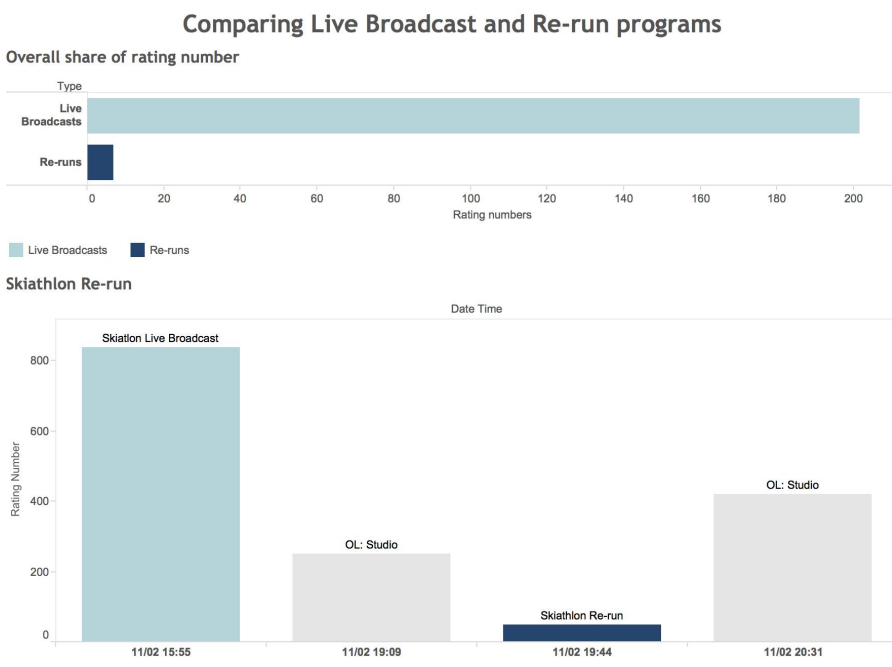

Figure 16. Comparison of Live-Broadcasting and Re-run Programs

original show had 838,000 viewers at 15:55, and at 19:45 its re-run had 48,000 viewers. This case clearly shows how viewers flee when re-runs are broadcasted. The studio show before and after drew more than 200,000 viewers and 400,000 respectively. The graphs clearly show that the re-runs yield far lower ratings. It is important to acknowledge when during the day most people are watching TV and allocate favorable shows to attract the largest share of viewers. Thus, it is important to revise and select appropriate timeslots for re-runs and allocate shows strategically.

\section{B. Actionable Insights}

1) Continue Doing More: As seen in Figure 4, broadcasting the Olympics leads to a steep increase in ratings during the event. Additionally, there is an increase in ratings after the event compared to before the event. Further, Figure 3 depicts how broadcasting the Olympic Winter Games positively affects social media engagement on Facebook. As such, TV2 should continue hosting the Olympics. The depiction of most popular 
shows in Figure 15, displayed that Cross Country skiing and Biathlon were significantly more popular than any other sport events. It is in TV2's interest to continue covering these events. Whether total ratings would increase if more time slots are allocated to Cross Country and Biathlon is unknown. However, showing less of the audience favorites seem unwise. Figure 5 on ratings distributed on hours of the day, and Graph Average Rating Number by Day of Week in Figure 5 on days of the week, inform that TV2s viewers, not surprisingly, watch most TV during weekends, and less during the night. Consequently, by optimizing and continue having the most popular sport events allocated to the most popular time slots and channels, TV2 can maximize potential ratings.

2) Continue Doing Less: Ratings of original broadcast shows and respective re-runs displayed in Figure 16, clearly reveals a significant preference for original shows. Re-runs in general have notably lower ratings, despite them being assigned popular time slots, as depicted in Figure 5 and Graph Average Rating Number by Day of Week in Figure 5. Consequently, allocating re-runs to popular time-slots is counter-effective and should be avoided. However, timezone differences between the hosting country and broadcasting country might prohibit an optimal broadcasting schedule for live events, allocating re-runs to popular time slots.

3) Do Differently (Improve): The sentiment analysis in Figure 5 revealed significantly lowered activity on TV2 Sporten Facebook wall during the "Good Event". Consequently, it is evident that TV2s social engagement team did not leverage the opportunity following the massive media coverage of the Good Event. Going forward, TV2 should optimize its social engagement capabilities to turn opportunities into growth. To do this, TV2 could analyze what social content stimulate activity. Figure 8 displaying emotional distribution of posts and comments, could provide valuable information to this analysis and contribute to an actionable plan.

4) Start Doing New: The graph Age Distribution During the Olympics in Figure 5 shows that the by far biggest group of viewers is in the age group 60+. This could entail that commercials, especially in certain hours of the day and days of the week should be tailored to this age group. The graph further shows that younger age groups have lower ratings. TV2 should create a strategy to entice younger demographics to watch the Olympics. However, as stated in the data set limitation, this study does not contain mobile device data. Younger demographics are both more reliant on mobile devices, and obligated to work and attend school. As such, providing their preferred content on mobile devices might influence their contribution to ratings. In addition, if TV2 air the already mentioned unpopular re-runs and niche events on a mobile device, the network will more effectively utilize time on the main channel.

5) Stop Doing Old: Figures 12 and 13 indicate the same finding; there is a direct relationship between the Bad Event, commercials and the presence of negative comments. TV2 aired commercials at inopportune times and thus exposed itself to the fury and anger of the public. When corrected for positive comments posted by TV2, the negative sentiment clearly outweigh the joy of excellent sports related accomplishments. As TV2 is a commercial broadcaster, it is dependent on airing commercials. However, to achieve a successful broadcasting event, it has to stop airing commercials at important moments in a program, or very early in the programs.

6) Do Not Do Ever: Based on the arguments in the above section, TV2 should never air commercials during the first part of a program or important situations. Despite the fact that a transition to a commercial broadcasting entailed a shock for the Norwegian audience, one finding seems clearly applicable for all broadcasters taking on a grand media sport event; do not ever show commercials interfering with important situations. However, the actionable insight discouraging the broadcast of commercials in early parts of programs may be culturally dependent, and thus only applicable to markets with a similar relationship and policy towards commercials.

\section{Discussion}

A. Research Question 1: How did consumer behaviour of the TV2 network change as a result of broadcasting the Olympic Winter Games of 2014?

In aiming to answer how behaviour changes as a result of the event in question, developments in ratings and Facebook activity has both been analyzed. A broad look at the data revealed that there are seasonal fluctuations in ratings. Normally, TV2 Sports News experiences an increase in ratings at the end of the year, with a peak around Christmas. In the start of January ratings decline until a bottom level is reached during the summer months. However, during the event in question, when TV2 were the official Olympic broadcaster in Norway, there was a deviation from the seasonal trend, i.e. the ratings had a steep increase in February 2014, as oppose to the decreasing seasonal trend. Note that this is only for the sports news and not the ratings of the actual olympic events. This implies that people not only look at the olympic event, but the surrounding broadcast as well. As such, this finding presents an increase in ratings during TV2s broadcast of the Winter Olympic Games.

Moreover, the ratings reveal that in March 2014 TV2 experience significantly higher than average ratings, and as such, indicating that the positive effect of the Olympics also had lasting effects. As there is no other significant broadcasting event or seasonal trend explaining the rating increase in March 2014 one can assume that it is related to TV2 broadcasting the Olympics. However, beyond this point in time, there is no indication of higher ratings or fluctuations from the trend. As such, these findings are on a stand alone basis inconclusive in attempting to answer the research question.

In February 2010, when NRK held the role as official Norwegian broadcaster, TV2s ratings were significantly lower than any other Februarys investigated. That is, when a broadcaster hosts a major sport event, competing broadcasters experience decreases in rating numbers. As such, a significant finding of this study is that while broadcasting a major media sport event increases a networks ratings, there are also substantial 
ramifications of not hosting it. Accordingly, sometimes one has to run to stand still - doing nothing changes consumer behaviour by reducing ratings. This finding is an important consideration for a broadcaster to take into account when deciding upon hosting a major sporting event. We found that although ratings were overall higher during the Olympics, a closer look at the event revealed a positive spike at start, and then declining interest throughout the event. This is also true for th the age group 60+, who had the highest rating numbers overall throughout the event window. As implied in the actionable insights and valuable outcomes, this can be related to mobile devices, and the change in focus of TV2 towards becoming a dominant interactive multimedia platform. The analysis of Facebook data supported the findings in the TNS rating data. Analysis revealed a significant increase in activity during the event. However, despite confirming increased activity during Bad Event, there were no evidence of a Good Event. Accordingly, these data indicate that commercials are attracting active engagement in social media, while the commentators, despite of attracting attention in other media outlets, are not engaging enough for the general audience.

The change in behaviour during the event were particularly revealing when analyzing unique actors on TV2 Sporten. We found that there were more than twelve times as many uniqe actors active per day during the event than before. Accordingly, broadcasting the event entails an extreme increase in activity from before, which indicates that broadcasting the Winter Olympics was a good decision. Despite a decrease in users from during the event to after, after still had twice as many users per day compared to before. As such, our findings entails a visible increase in behaviour after the event, compared to activity and engagement before. The trendline of overall Facebook activity confirms this finding.

Summarized, the event study finds that Sports News ratings increase immediately after TV2 broadcasted the Olympics. However, there are no visual support for arguing a long-term effect throughout the complete event window. The Facebook activity increases after the event, and keeps rising throughout the entire event window. Accordingly, more users are active on TV2 Sporten Facebook page. As such, the two data sets present the same findings, and support the following conclusion; after TV2 broadcasted the Olympics there was a positive change in behaviour, entailing short-term higher ratings and long-term higher engagement.

B. Research Question 2: How was consumer opinion of the TV2 network affected during the Olympic Winter Games of 2014 ?

The consumer opinion of TV2 were affected both in terms of level of opinionated engagements and type of sentiment, both within the event and the complete event window. When analysing the complete event window, we found evidence of increased sentiment towards TV2 during the pre-event window, culminating in a peak of negative and positive brand sentiments during the event. Further, the study showed a decrease in opinionated engagements throughout the engagement window.
As the level of consumer opinions relating to TV2 remains higher after the event, our event study finds that broadcasting the Olympics led to more opinionated actors.

After the event, the neutral comments remained high and increasing, while positive and negative comments seem to correlate at a lower level throughout the complete event window. Interestingly, through the entire event there is a higher level of negative engagements compared to positive ones. As the level of opinions were lower before the event, we can conclude that there has been a change in sentiment towards TV2 when comparing before and after the event.

The highest presence of brand related sentiment were observed at the beginning of the Winter Olympics. This finding provides a final evidence confirming the existence of Bad Event, while rejecting Good Event. This period had an extensive amount of negative posts and comments, culminating in a peak the third day showing almost exclusively negative comments. However, subsequently the negative sentiments normalize at a lower level. Combined with the findings above, this decrease in negative sentiment engagement after Bad Event could be explained by a change in behaviour, i.e. as depicted by ratings, interest declines during the course of the event. In other words, that viewers left the channel after the Bad Event. One can ask if this was due to an excessive amount of commercials at inconvenient times. The decline could also be the consequence of better scheduling of commercials. However, the higher level of negative opinion after the event suggests that this is not the case, as the findings would then not resonate after the event window. A third explanation might be TV2 limiting collateral damage. We found an increase in general activity by TV2 during Bad Event, and that this activity were mainly positive. This indicates that TV2 might have impacted the overall opinion towards itself positively, being the direct cause of the consumer opinion.

We found that both during Bad Event and the event window, the most used word on TV2 Sporten was commercial, even surpassing expected words such as congratulations. Accordingly, we conclude that there is a strong link between commercials, the bad events and negative sentiment. This proves our initial assumptions, and validate the research. An interesting finding is also that the majority of text engagement were posts, during the bad event window. This entails that people are actively looking up the Facebook page, wanting to express their opinion, rather than just respond to others engagements. Accordingly, this increases the significance of the negative opinion. As such, we conclude that consumer opinion were negatively affected by the transition from NRK to TV2, and that the negative sentiment were based on the presence of commercials.

\section{Research Question 3: How did consumer opinion towards TV2 and NRK differ during the Olympic Winter Games of 2014 ?}

The consumer opinion towards TV2 and NRK differed during the 2014 Olympic Winter Games. Our analysis was based on Bad Event where TV2 aired commercials at the 
inconvenience of its audience. The incident was greatly reflected in sentiment analysis, which revealed stronger negative connotations on the TV2 Sporten Facebook wall than on NRK Sport. Word clouds showed that contextually negatively charged words like commercial was the most commonly used words in posts and comments on TV2 Sporten. On the contrary, contextually positively charged words like missing and back were the most commonly used words on NRK Sport. This indicates a stronger negative engagement towards TV2 Sporten than NRK Sport. This were further supported when comparing average brand sentiment distribution for the total event period, with brand sentiment distribution during $\mathrm{Bad}$ Event. This analysis revealed a significant increase in total negative engagements during Bad Event on TV2 Sporten, whereas positive engagements increased in the same period on NRK Sport. Consequently, the consumer opinion towards TV2 was significantly more negative than opinions towards NRK, who in fact, had an increase in positive opinions. As such, we conclude that TV2 and NRK differ significantly in dominant sentiment. There is a direct link between negative sentiment on TV2 and the presence of commercials.

Regarding limitations of our work, choosing a different country might have yielded other findings. In this study, Norway was the country of interest and Norwegians has a specially strong affiliation to winter sports, and will sacrifice much to watch it. Accordingly, this is only representative for Norway and other countries with similar interest level in the considered sporting event as Norway.

\section{ACKNOWLEDGEMENTS}

The last four authors of the paper were partially supported by the Industriens Fond (The Danish Industry Foundation). Any opinions, findings, interpretations, conclusions or recommendations expressed in this paper are those of its authors and do not represent the views of the Industriens Fond (The Danish Industry Foundation).

\section{REFERENCES}

[1] C. Kang, "Bidding war between networks, sports leagues will increase price of cable tv," https://www.washingtonpost.com/business/economy/ bidding-war-between-networks-sports-leagues-will-increase-price-of-cable 2015/01/23/d0cb19f4-9db8-11e4-a7ee-526210d665b4_story.html, January 2015 .

[2] A. Tomlinson and C. Young, National identity and global sports events: Culture, politics, and spectacle in the Olympics and the football World Cup. SUNY Press, 2006.

[3] A. Kolstad, "Når nasjonen vinner - om underholdningsidrettens betydning for moderne nasjonalisme," Psykologisk institutt, NTNU, Tech. Rep., 2002.

[4] R. G. Noll, "Broadcasting and team sports," Scottish Journal of Political Economy, vol. 54, no. 3, pp. 400-421, 2007.

[5] E. Katz and D. Dayan, "Media events: The live broadcasting of history," Cambridge, MA: Harvard UP, 1992.

[6] L. S. S. Ugulen, "Ol 2014 på tv 2-en mediebegivenhet på alle dine skjermer," Master's thesis, The University of Bergen, 2014.

[7] J. Scherer and M. P. Sam, "Public broadcasting, sport and cultural citizenship: Sky's the limit in new zealand?" Media, culture \& society, vol. 34, no. 1, pp. 101-111, 2012.
[8] J. Scherer and D. Whitson, "Public broadcasting, sport, and cultural citizenship the future of sport on the canadian broadcasting corporation?" International Review for the Sociology of Sport, vol. 44, no. 2-3, pp. 213-229, 2009.

[9] A. Bruns, D. Dr Katrin Weller, and M. Bober, "Twitter and tv events: an exploration of how to use social media for student-led research," Aslib Journal of Information Management, vol. 66, no. 3, pp. 297-312, 2014.

[10] A. M. MacEachren, A. Jaiswal, A. C. Robinson, S. Pezanowski, A. Savelyev, P. Mitra, X. Zhang, and J. Blanford, "Senseplace2: Geotwitter analytics support for situational awareness," in Visual Analytics Science and Technology (VAST), 2011 IEEE Conference on. IEEE, 2011, pp. 181-190.

[11] J. Jussila, K. Menon, R. R. Mukkamala, L. A. Lasrado, A. Hussain, R. Vatrapu, H. Kärkkäinen, and J. Huhtamäki, "Crowdfunding in the development of social media fanbase - case study of two competing ecosystems," in proceedings of 49th Hawaii International Conference on System Sciences, 2016.

[12] C. O. Alm, D. Roth, and R. Sproat, "Emotions from text: machine learning for text-based emotion prediction," in Proceedings of the conference on human language technology and empirical methods in natural language processing. Association for Computational Linguistics, 2005, pp. $579-586$.

[13] E. Fonden, "Egmont fonden annual report 2014." http://issuu.com/ egmontcomm/docs/egmont_annual_report_2014_english_/1, March 2015.

[14] TNS Gallup AS, “Årsrapport for tv-seing 2014.” www.tns-gallup.no. 2014.http://www.tns-gallup.no/tns-innsikt/arsrapport-for-tv-seing-2014, November 2015.

[15] D. Mysore, S. Khupat, and S. Jain, "Big data architecture and patterns, part1: Introduction to big data classification and architecture," IBM Corp, 2013.

[16] A. Hussain and R. Vatrapu, "Social data analytics tool (sodato)," in DESRIST-2014 Conference (in press), ser. Lecture Notes in Computer Science (LNCS). Springer, 2014.

[17] — _ "Social data analytics tool: Design, development, and demonstrative case studies," in Enterprise Distributed Object Computing Conference Workshops and Demonstrations (EDOCW), 2014 IEEE 18th International, Sept 2014, pp. 414-417.

[18] C. Cioffi-Revilla, Introduction to Computational Social Science: Principles and Applications. Springer Science \& Business Media, 2013.

[19] Y. Yang and X. Liu, "A re-examination of text categorization methods," in Proceedings of the 22nd annual international ACM SIGIR conference on Research and development in information retrieval. ACM, 1999, pp. 42-49.

[20] H. Zhang and D. Li, "Naive bayes text classifier," in Granular Computing, 2007. GRC 2007. IEEE International Conference on. IEEE, 2007, pp. 708-708.

[21] S. Bird, "NLTK: the natural language toolkit," in Proceedings of the COLING/ACL on Interactive presentation sessions. Association for Computational Linguistics, 2006, pp. 69-72.

[22] B. Flesch, R. Vatrapu, R. R. Mukkamala, and A. Hussain, "Social set visualizer: A set theoretical approach to big social data analytics of real-world events," in Big Data (Big Data), 2015 IEEE International Conference on. IEEE, 2015, pp. 2418-2427.

[23] Benjamin, Flesch, A. Hussain, and R. Vatrapu, "Social set visualizer: Demonstration of methodology and software," in Enterprise Distributed Object Computing Workshop (EDOCW), 2015 IEEE 19th International, Sept 2015, pp. 148-151. 